\title{
The Technology Method Research Of Scrap Ammunition Destruction
}

\author{
Haibo Liu ${ }^{1, a}$, Yidong Wang ${ }^{2, b}$ and Hongjuan Zhu ${ }^{3, c}$ \\ ${ }^{1,2}$ the $91872^{\text {th }}$ unit of PLA, Beijing, China \\ ${ }^{3}$ Department of naval equipment, Beijing, China \\ a'wangjunshen1024@126.com, 'bangyidong96107@163.com, ${ }^{\mathrm{b}}$ zhuhongjuan1024@126.com
}

Keywords: ammunition weapon; discard destroyed; decentralized control; focus on; remove technology

\begin{abstract}
The processing of scrap ammunition is an activity that reduces scrap ammunition dangerous properties and solves the problem of ammunition security retirement by the use of various technology methods and means. The foreign ammunition destruction situation and ammunition destruction at various stages are introduced in this paper. The technical methods of scrap ammunition destruction adopted in China are introduced detail at last. The technical method described in this paper has very important reference value for the destruction of weapon ammunition.
\end{abstract}

\section{Introduction}

The processing of scrap ammunition is an activity that reduces scrap ammunition dangerous properties and solves the problem of ammunition security retirement by the use of various technology methods and means. The process design of destroyed should always around eliminating threat to people, goods, objects, the pollution to the environment, recycling resources etc. The application of science technology and scientific research achievements can reduce the working strength, the production cost, improve the labor safety and work efficiency. The choice of scrap ammunition processing methods depends on the ammunition, powder materials, processing target, processing technology and environmental conditions[1-5]. Single technology methods often cannot achieve the purpose of ammunition destruction, almost all the ammunition handling is the result of the integrated application of ammunition disposal technology. The commonly used destruction technology has decomposition technology, empty technology, burning technology, blowing up technology etc[6-8].

\section{Destruction Situation of Foreign Ammunition}

In the 1970s, the United States published many processing scrap ammunition technology patents. After the 1980s, many achievements have been made in the field of the ammunition metal material and comprehensive utilization of the explosive fire. Germany introduced foreign ammunition disposal equipment actively. Their own professional waste institutions were set up. The scrap ammunition processing work has been accelerated. In the early 1990s, the world famous Swedish Bofors $\mathrm{AB}$ implements merger and acquisition for FFV company. It is responsible for the development and production of ammunition destruction equipment, undertakes other countries' ammunition destruction, provides technology and equipment of ammunition destroy for foreign, becomes a great influence company in the world's ammunition destruction industry. At present, scrap ammunition processing technology method around the world includes decomposition disassembled, cut down and burned with control etc[9-15]. The technology of recycling waste explosives has become mature. Equipment isolation operations, personnel protective security and automation level is higher and higher. Ammunition processing has developed towards automation control technology direction. The typical mainly includes: shells disassembly machine researched by Swedish Bofors AB company, destruction system researched by bofors AB company and Dana villejuif company, the explosion cutting ammunition technology of Russian, hot water cut down equipment of Joseph tesla company of Germany, artillery sawing machine and abrasive water jet 
cutting equipment of American. In addition, the typical equipment is "flexible table" developed by the United States. The "flexible table" is made up of five explosion-proof chambers and is controlled by computer. Robots take out ammunition from the packaging and remove the fuse remove ammunition from the packaging and remove the fuse in these workshops. The projectile is separated from the cartridge. Primer and propellant charge are taken out. Then the explosive of projectile can be taken out. Special software can make robots have "feeling" function, operate according to the circumstance, become a flexible tool. The staff are not needed in the scene because of robots and the application of computers. The processing speed of scrap ammunition speeds up. Spending reduces. The whole process becomes more safe and effective[16-17].

Whether a kind of ammunition should be destroyed or not, its life should be analyzed first. So below a kind of degradation failure concept about life is introduced as follows.

\section{Definition on the Life Variable of Degradation Failure}

Assume the degradation amount of the product at $t$ is $y(t)$, degradation failure is defined as: when the degradation amount varies with the time, reaching a predetermined failure criteria $D_{f}$, then the failure occurs. The corresponding time is the life of the product (or the time to failure). Thus the life can be defined as

$$
T_{D}=\inf \left\{t: y(t)=D_{f} ; t \geq 0\right\}
$$

In some practical issue, constantly, the reliability could be indicated by the ratio of $y(t)$ to its initial value $y(0)$ (or the initial value of the degradation amount of product)[15-17]. If $y(t) / y(0)$ reaches the failure criterion, then determine the product is failure, and its failure life is written as

$$
T_{R}\left(D_{f}\right)=\inf \left\{t: \frac{y(t)}{y(0)}=D_{f} ; t \geq 0\right\}
$$

Formula (1) is defined by the ratio of degradation amount to the initial value, so it is called relative failure criteria, correspondingly, formula (2) is called absolute failure criteria.

\section{Experienced Stages of Scrap Ammunition Destruction}

Abandoned Destruction Stage. Until the 1950s, due to the restriction factors such as social, economic and technical conditions at that time, the government did not attach enough importance to the processing of scrap ammunition. The simple and irresponsible way were adopted to deal with scrap ammunition by many governments and organizations, such as abandoned, buried, discard into the deep sea or abandoned mine. These handling ways are simple and irresponsible. The danger still exist after scrap ammunition was abandoned.

Phase of Burned and Blow up. In the 1950s to 70s, as the large-scale war ceases, people have the energy to study the processing problems of scrap ammunition. The way of dumping into the ocean is opposed by environmental groups. The handling way turns to burn, blasting destruction step by step. The way of combustion and blow up requires a lot of manpower, material and financial resources. The serious air pollution and noise pollution can be caused at the same time. The resource wastes serious. Countries noted the importance of environmental protection. The laws of ammunition destruction and regulations to prevent environmental pollution are formulated successively. The processing methods of scrap ammunition are started trying to use such as simple manual remove, heating empty method. The accidents often happen in this phase. The large harm and influence have appeared. The processing work gets the attention of the governments and the army gradually.

Phase of limiting Burned and Blow up. After the 1970s, along with the advance of social civilization, the damage of uncontrolled open fires and blow up to the environment can not adapt to the requirement of era development. Governments increasingly attach great importance to the problems brought by the scrap ammunition. The investment is increased gradually. The handling 
methods of meeting the requirements of environmental protection are researched. The ordnance department of all countries begins to standard ammunition processing work, and the destruction research institutions and professional destruction organization are established. All kinds of ammunition handling procedure are reviewed. The new processing process and methods of scrap ammunition is researched. The safe and efficient of handling are ensured. The pollution is reduced. The cost is reduced. The processing of scrap ammunition turns toward the developing mode of safety, environmental protection, low consumption step by steps.

Attaching Great Importance to the Environmental Destruction Phase. Into the 1980s, the processing of scrap ammunition gradually formed the scale in Europe, America and other western developed countries. And the benefits can be gained from the processing of scrap ammunition. It became a new industry. Thus, some professional organization that engaged in destructing and recycling scrap ammunition set up, such as NAMSA、NADC、NAMMO of Nordic、ISL of Germany AF Demil of France FAEX of Spain、Cheddite Italiahe and Esplodenti Sabio of Italian、 TBET 、CATI etc. The destroy method adopted by all countries mainly includes ammunition decomposition disassembly method、controlled burning and blow up method、 biological chemical method etc. Automatic control technology, low/high temperature technology, high pressure fluid technology and robot technology are adopted to destruct scrap ammunition at the same time.

\section{Technology Methods of Scrap Ammunition Disposal Used by Our Country}

Combination of Decentralized Control and Centralized Processing. Waste ammunition is dispersed in each unit. Grassroots units lack technology and equipment of scrap ammunition process, do not have ammunition destruction condition. Each unit shall not process scrap ammunition arbitrarily. The scrap ammunition should be managed and controlled by normal channels. The scrap ammunition is destroyed by adopting the way of combination decentralized and centralized. If the ammunition is dangerous and inconvenience to transfer, they can be destroyed by professional destruction institutions. If the transport safety of ammunition can be improved by decomposition technology, the sensitive element is removed first by professional teams carrying mobile equipment. The risk of ammunition explosion is reduced. Sensitive components are burned. The projectiles are transferred to professional institutions to destruct.

Adopting the Process of Conforming the Environmental Protection Requirements. The pollution source in ammunition is mainly explosive material of ammunition. Harmless to the environment technology methods should be adopted. At present, some technology methods can achieve pollution-free processing such as emission charge poured out, TNT charge projectile empty. Decomposition technique can separate inert materials of ammunition with other materials by the help of equipment or artificial. The element that does not contain gunpowder can be recycled directly after disassembly. Cartridge can be recycled directly. Process does not produce any pollution. Heating separation can separated projectile shell with explosive by using steam heating technology, hot air heating technology, hot water to take off technology etc. The above technology methods do not produce waste water, also do not have other wastes to discharge, conform to the requirements of environmental protection, are worth promoting.

Using Appropriate Technology Route. Scrap ammunition has characteristics of many varieties, large quantity, inflammable and explosive. The risk in the process of scrap ammunition processing and ammunition accident harm determines the scrap ammunition processing technology difficult. If scrap ammunition processing method is undeserved, environment can be polluted or safe hidden trouble can be caused. If processing methods is proper, environmental pollution and safety hidden trouble can be eliminated thoroughly[37-38]. Useful resources can also be recycled. The destruction of each kind of scrap ammunition needs to develop a detailed process in order to ensure the safety of ammunition destruction. The removal processing of scrap ammunition to meet environmental requirements 、 reducing the risk of operation、 recovery of useful resources can be ensured by this way. The classify process of batch scrap ammunition destruction should be considered. The same 
process technology and unified management measures are used to process the same types of ammunition. The advanced and practical equipments are researched for different types of ammunition. The scientific research project was done at first for the ammunition of destruction difficult. The key process methods and equipment were research. Small scale experiment was carried out first, try to destroy. The reasonable safety engineering and technical parameters are obtained. The correct matching efficient technology route was formed finally after inspection. In the practice of the scrap ammunition disposal technology, the formation of technical route usually includes information research, project demonstration, preliminary design, analyze problems, solutions, expert appraisal, technical implementation.

\section{Conclusion}

The scrap ammunition disposal technology method adopted by our country is expounded in detail in this paper. Mainly includes: adopting decentralized control combined with concentrated handle, adopting process method complying with the requirements of environmental protection, adopting appropriate process technology route etc. If processing methods is proper, environmental pollution and safety hidden trouble can be eliminated thoroughly. The useful resources can be also recycled. It has great significance for improving security, reliability and economic effect of scrap ammunition destruction.

\section{References}

[1] Jiang Yue-fei, Zhang Zheng-zhong, Yang Yan, Wang Zhong-guo. The design and construction of scrap ammunition destruction[J]. Engineering blasting,2019,15(2):87-90.

[2] Luo Zhi-li. Several realizations of disposal war legacy shells[J]. The guangdong public security science and technology, 2004,(4):64-66.

[3] Lou Jian-wu, Long Yuan, Xie Xing-bo. Disposal and destruction technology of abandoned explosives and conventional ammunition[M]. Beijing: National Defence Industry Press,2007:155-228.

[4] Hu Zhen,Liu Chu-ping, Shu Fu-gui. The research of thermal plasma technology destruction Japanese abandoned chemical weapons filler[J]. Journal of safety and the environment,2006,6(6):84-87.

[5] Zhang Jie, Gao Yu-shan. The design and organize implementation of waste bombs destruction[J].Benxi steel technology, 2008( 2) : 1-3.

[6] Fu Jian-qiu, Hu Xiao-long, Liu Yi. The processing of residual waste shells and gas bomb in our country[J]. Engineering blasting, 2007,13(2):74-77.

[7] Yuan Shao-guo, Zhang Fu-gui, Zhang Pei-rui. The blasting destruction of waste bomb in Baotou city[J]. Engineering

[8] Wang Wei, Cai Rui-jiao, Jiao Qing-jie. The research of guided munition reliability assessment method[J]. Journal of ordnance,2007(7):41-47.

[9] Xu Xiang-guo, Zhao Xiao-li. The prediction method discussion of a certain type guidance ammunition storage life[J]. Journal of sichuan armaments ,2007(3):61-64.

[10] Sun De-fu. The research of ammunition reliability data analysis method[J]. Journal of missile and guidance,2009(4):24- 28.

[11] Kleyner A. Bayesian techniques to reduce the sample size in automotive electronics attribute testing [J].Microelec Tronics Reliability, 1997, 37(6) : 879- 883.

[12] Zhang Shif eng. Bayesian assessment for product reliability using pass out data [J]. Acta 
Armamentarii, 2001, 22( 2) : 238-240. ( in Chinese)

[13] Xiao Gang. Reliability assessment of solid rocket engine based on converted information [J] . Journal of Xian Jiaotong University,1999, 33( 7) : 33- 36. ( in Chinese)

[14] Zhou Ming-an, Xia Jun, Xiao Zhi-wu. Inspection and destruction discussion of war explosive remnants[J].Blasting, 2007, 24( 2) : 82-86.

[15] Zhai Xin-fu, Ying An-ming, Nie Cheng-yue. The safety issues and countermeasures in the process of waste ammunition destruction[J]. Journal of sichuan armaments factories,2002,23(4):36-37.

[16] Li Jin-ming, Gao Xin-bao,Ding Yu-kui. Accident prevention measures in the process of scrap ammunition blasting destruction[J].Blasting, ,2011,28(3):116-118.

[17] Yi Jian-kun, He Wu-yi,Wu Teng-fang. High hot agent application in the field of ammunition destruction[J]. Engineering blasting,2004,10(4):21-25. 